I note from their table II that there was a marked rise in blood glucose level after the infusion of glucose which was not seen when sorbitol, fructose, or saline was given. The advantage of glucose over fructose or sorbitol is that it demonstrates by such a rise in blood sugar the presence of the "diabetic-like state," similarly encountered in some patients after acute stress by the inhibition of insulin secretion by adrenaline and sympathetic overactivity. It would seem likely that had Dr Ames and his colleagues included a further group of women to whom he had given with the glucose sufficient exogenous insulin to prevent hyperglycaemia this group would also have shown a reduction in ketones but with no rise in blood lactate. Froesch ${ }^{2}$ has pointed out that during muscular work (for example, during labour) glucose is taken up by muscle cells even in the absence of insulin. Its fate, however, is then different, in that it is almost entirely converted to lactate. Under normal conditions the lactate will be metabolised in the liver, but this is prevented when sufficient sorbitol or fructose is infused and also metabolised to lactate in the liver. In the "diabetic-like state" lactate will then accumulate in the blood. ${ }^{3}$

It has been my experience in treating cases of acute or chronic renal failure complicated by a diabetic response that infusions of glucose accompanied by sufficient insulin to maintain the blood sugar strictly within the normal range prevent both ketosis and lactic acidosis. The advantage of glucose is that its blood level is readily monitored, whereas, as shown by $\mathrm{Dr}$ Ames and his colleagues, sorbitol or fructose can produce lactic acidosis without any concomitant rise in the blood sugar. I would suggest, therefore, that glucose with added insulin would fulfil their requirements for a substrate to infuse to women in labour for the treatment of ketonaemia without raising the blood lactic acid level. When insulin is infused at a rate of about one unit per $3 \mathrm{~g}$ of glucose hyperglycaemia is unlikely to occur, and none of our cases has become complicated by hypoglycaemia.

Department of Nephrology

Southmead Hospital, Bristo 1 Porte, D, Jr, et al, fournal of Clinical Investiga-

Froesch. E R, and Keller, U, in Parenteral Nutrition, ed A W Wilkinson. Edinburgh and London, Churchill Livingstone, 1972 .
Woods, H F, and Alberti, K G M Mancet, $1972,2,1354$.

\section{Cancer statistics}

SIR,-Dr R F Mould's criticisms of cancer statistics (10 January, p 86) referred to the registration procedure and the Department of Health and Social Security statistical return $\mathrm{SH} 3$. The former is a matter for the Office of Population Censuses and Surveys; my immediate concern is to point out the inaccuracies and misunderstandings present in the criticism of the $\mathrm{SH} 3$ return.

There is evident confusion in Dr Mould's interpretation of the data collected in part 2 and part 3 of the form. The former records patients attending for consultation with medical staff whereas the latter is concerned with attendances for treatment not necessarily in the presence of medical staff. Patients attending for consultation do not necessarily attend a treatment department and vice versa. In general the counts in parts 2 and 3 will not correspond and the relative sizes of the consultation and treatment counts at department level will depend on specific characteristics such as the type of service provided and referral patterns.

Dr Mould appears to have been misled by the identical figures for new outpatient consultation and treatments for two of the hospitals in his sample. Far from being the typical situation, these events are due to particular features of the radiology departments concerned. In one case, for example, it is known that all patients attending the radiotherapy department for the first time do so for treatment, the need having been confirmed elsewhere.

In the absence of specific instances the allegation of general ambiguity in the instruc tions for completing the form can be answered only in broad terms in a letter such as this The treatment and care of patients are the responsibility of consultants; practice varie widely and it is very difficult to reflect thi in a summarised statistical report such a SH3, which offers only a broad framework for measurement of hospital activity. Detailed notes are issued annually and the inevitable compromise has to be struck between excessive detail and insufficient guidance for consisten recording. These notes are reviewed every year both in response to known changes in the provision of care and as a result of queries received, generally from hospital medical records officers. I do not, of course, claim complete accuracy for every figure on each of the 3000 returns received annually. There ar problems of misinterpretation of instructions, and recording errors do occur. Each return is subject to reasonable validation centrally, consistent with the accuracy required for the uses of the return.

For hospital statistics in general a single definition of new outpatient is in use and this relates to the first consultation or the commencement of treatment for a particular complaint. In radiotherapy post-treatment monitoring may continue for years following formal discharge to the care of a general practitioner. There may be a tendency to view recommencement of treatment as a continuation of a previous episode and to fail to record this as a new episode. This will affect both consultations and treatments and hence the balance between the two will remain unchanged. However, total work load as measured by attendances will be counted correctly.

\section{F E WHITEHEAD} Chief Statistician, Statistics and Research Division,
Department of Health and Social Security London $\mathrm{WCl}$

\section{Modern obstetrics and the general practitioner}

SIR,-I was surprised to find no mention in the article by Professor E Wilkes and others (20 December, $p$ 687) of the need for GP obstetricians to become competent in the care of the newborn infant.

Now that maternal mortality has reached near rock-bottom perinatal mortality and morbidity have become a major concern to obstetricians; and if domiciliary midwifery is to survive, as I hope it will, and 24-48-hour admission to become the mode in maternity units it is the more important that those responsible for mother and baby should be able to undertake the resuscitation of either than to act as a midwife or subconsultant and also that they should be familiar with the medical management of neonatal problems, including feeding, infection, jaundice, and congenital anomalies.

It is to be hoped that in future neonatology will once more become a mandatory part of obstetric training for GPs and consultants. Otherwise, for the baby, birth will be safe only in large units with a 24-hour paediatric service.

University Department of Child Health

J A Davis St Mary's Hospital, Manchester

\section{Surgical policy after Cyclone Tracy}

SIR,-In his "Letter from South Australia" (16 August, p 419) Professor P Rhodes states: "the surgical policy was to excise wounds and primarily suture the skin, prior to evacuation." All surgeons of the armed Services will know full well the hazards involved in dealing with raumatic wounds by primary suture, and they will not be surprised to hear that there were a number of infective complications in the patients whose wounds were so treated at Darwin. These included some cases of gas gangrene.

As consultant surgeon to the Royal Australian Army Medical Corps it is my duty to point out that it remains our policy to deal with all traumatic wounds by delayed primary closure. This means that after proper excision of the damaged tissue the wound is left open for three or four days, after which it is closed either by direct suture or by the application of split skin grafts. Only by this method are such wounds rendered safe-safe against the hazards of anaerobic infection, safe against the hazards of primitive conditions and lack of supervision during evacuation. I am sure that all military surgeons will agree that no antibiotic cover is adequate to allow the treatment of these wounds by primary suture.

The surgeons of Darwin who worked under such adverse conditions a year ago now admit freely that their policy of primary suture for such wounds should not be taken as a precedent for the future. The only safe way to manage traumatic wounds is by delayed primary closure.

Douglas LesLie

East Melbourne,
Victoria, Australia

\section{Hypothermia associated with nitrazepam} administration

SIR,-We wish to report a case of hypothermia which occurred in an elderly patient following the administration of $5 \mathrm{mg}$ of nitrazepam.

A woman aged 86 was admitted to the geriatric unit of this hospital in March 1975 with a one-year history of senile dementia, malnutrition, and iron deficiency anaemia. She was transferred to our long-stay wards on 16 July after successful treatment of her anaemia but an unsuccessful attempt at rehabilitation, being disorientated in time and space, incontinent of urine, and chair/bed-bound. She was then receiving no medication. At $10 \mathrm{pm}$ on 27 July she was given $5 \mathrm{mg}$ of nitrazepam, having been restless and sleepless the night before. At $10 \mathrm{am}$ on the following morning she was drowsy, her pulse was $56 / \mathrm{min}$, her blood pressure was $105 / 55 \mathrm{~mm} \mathrm{Hg}$, and the skin on her abdomen, felt cold. Her rectal temperature was $33.9^{\circ} \mathrm{C}$ 